\title{
Prostate Cancer Patients' Survival Expectations With and Without Their Chosen Treatment
}

\author{
Nicole Gentile, PbD, Editorial Advisory Board member and Michael E. Johansen, MD, Editorial Fellow \\ Ann Fam Med 2016;14(3):iii. doi:10.1370/afm.1947.
}

The Annals of Family Medicine encourages readers to develop a learning community of those seeking to improve health care and health through enhanced primary care. You can participate by conducting a RADICAL journal club. RADICAL is an acronym for Read, Ask, Discuss, Inquire, Collaborate, Act, and Learn. Radical also indicates the need to engage diverse participants in thinking critically about important issues affecting primary care and acting on those discussions. ${ }^{1}$

\section{HOW IT WORKS}

In each issue, the Annals provides discussion questions for a selected article. We encourage you to take a RADICAL approach to these materials and to post a summary of your conversation in our online discussion. (Open the article online and click on "TRACK Comments: Submit a response.") You can find more information at: http://www.AnnFamMed.org/AJC/.

\section{CURRENT SELECTION}

\section{Article for Discussion}

Xu J, Janisse J, Ruterbusch JJ, et al. Patients' survival expectations with and without their chosen treatment for prostate cancer. Ann Fam Med 2016;14(3):208-214.

\section{Discussion Tips}

Rarely do scientific publications selected for jounal club provide insight from a patient's perspective of disease. That perspective influences decision making and the perception of life expectancy. This study investigates the expectations of patients with localized prostate cancer for survival with and without their chosen treatment.

\section{Discussion Questions}

What question is asked by this study and why does it matter to a family physician?

- Discuss strengths/weaknesses of the study design.

- To what degree can the findings be accounted for by:

1. How patients were selected, excluded, or lost to follow-up?
2. How were the main variables measured and what others could alter a patient's perception of disease severity or decision-making (eg, marital status)?

3. Could the results have been influenced by a nonresponse bias given the response rate of $68 \%$ ?

4. Confounding (false attribution of causality because 2 variables discovered to be associated actually are associated with a 3 rd factor)? How might physician-patient dynamics influence patient perception of life expectancy?

5. Chance?

- What are the main study findings?

- How comparable is the study sample to similar patients in your practice?

-What contextual factors are important for interpreting the findings? ${ }^{2-3}$

- Will this study change your practice? Is it applicable to other disease states and treatment decisions? ${ }^{4}$

- What tools can help educate patients and facilitate discussions on realistic life expectancy? $?^{5}$

- How might primary care clinicians engage in important treatment decisions such as localized prostate cancer that are frequently made external to their clinics?

- Reflect on factors in your life that may affect your perception of disease severity and how these factors might influence your treatment decisions?

\section{References}

1. Stange KC, Miller WL, McLellan LA, et al. Annals Journal Club: It's time to get RADICAL. Ann Fam Med. 2006;4(3):196-197.

2. American Cancer Society. Watchful waiting vs active surveliance for prostate cancer. http://www.cancer.org/cancer/prostatecancer/ detailedguide/prostate-cancer-treating-watchful-waiting. Accessed Mar 15, 2016.

3. Sommers BD, Beard CJ, D'Amico AV, Kaplan I, Richie JP, Zeckhauser RJ. Predictors of patient preferences and treatment choices for localized prostate cancer. Cancer. 2008;113(8):2058-2067.

4. Kureshi F, Jones PG, Buchanan DM, Abdallah MS, Spertus JA. Variation in patients' perceptions of elective percutaneous coronary intervention in stable coronary artery disease: cross sectional study. BMJ. 2014;349:g5309.

5. Lee SJ, Boscardin WJ, Kirby KA, Covinsky KE. Individualizing life expectancy estimates for older adults using the Gompertz Law of Human Mortality. PLoS One. 2014;9(9):e108540. 